Louisiana State University

LSU Digital Commons

Faculty Publications

Department of Biological Sciences

2-15-2013

\title{
Variation in sodium current amplitude between vasopressin and oxytocin hypothalamic supraoptic neurons
}

\author{
Reese Scroggs \\ University of Tennessee Health Science Center \\ Lie Wang \\ University of Tennessee Health Science Center \\ Ryoichi Teruyama \\ Louisiana State University \\ William E. Armstrong \\ University of Tennessee Health Science Center
}

Follow this and additional works at: https://digitalcommons.Isu.edu/biosci_pubs

\section{Recommended Citation}

Scroggs, R., Wang, L., Teruyama, R., \& Armstrong, W. (2013). Variation in sodium current amplitude between vasopressin and oxytocin hypothalamic supraoptic neurons. Journal of Neurophysiology, 109 (4), 1017-1024. https://doi.org/10.1152/jn.00812.2012

This Article is brought to you for free and open access by the Department of Biological Sciences at LSU Digital Commons. It has been accepted for inclusion in Faculty Publications by an authorized administrator of LSU Digital Commons. For more information, please contact ir@lsu.edu. 


\title{
Variation in sodium current amplitude between vasopressin and oxytocin hypothalamic supraoptic neurons
}

\author{
Reese Scroggs, ${ }^{1}$ Lie Wang, ${ }^{1}$ Ryoichi Teruyama, ${ }^{2}$ and William E. Armstrong ${ }^{1}$ \\ ${ }^{1}$ Department of Anatomy and Neurobiology, University of Tennessee Health Science Center, Memphis, Tennessee; \\ and ${ }^{2}$ Department of Biological Sciences, Louisiana State University, Baton Rouge, Louisiana
}

Submitted 12 September 2012; accepted in final form 20 November 2012

Scroggs R, Wang L, Teruyama R, Armstrong WE. Variation in sodium current amplitude between vasopressin and oxytocin hypothalamic supraoptic neurons. J Neurophysiol 109: 1017-1024, 2013. First published November 21, 2012; doi:10.1152/jn.00812.2012.-Biophysical characteristics of tetrodotoxin-sensitive sodium $\left(\mathrm{Na}^{+}\right)$currents were studied in vasopressin (VP) and oxytocin (OT) supraoptic neurons acutely isolated from rat hypothalamus. $\mathrm{Na}^{+}$current density $(\mathrm{pA} / \mathrm{pF})$ was significantly greater in VP neurons than in OT neurons. No significant difference between VP and OT neurons was detected regarding the voltage dependence of activation and steady-state inactivation, or rate of recovery from inactivation of $\mathrm{Na}^{+}$currents. In both VP and OT neurons, the macroscopic inactivation of the $\mathrm{Na}^{+}$currents was best fitted with a double-exponential expression suggesting two rates of inactivation. Also in both types, the time course of recovery from inactivation proceeded with fast and slow time constants averaging around 8 and $350 \mathrm{~ms}$, respectively, suggesting the presence of multiple pathways of recovery from inactivation. The slower time constant of recovery of inactivation may be involved in the decrease in action potential (AP) amplitude that occurs after the first spike during burst firing in both neuronal types. The larger amplitude of $\mathrm{Na}^{+}$currents in VP vs. OT neurons may explain the previous observations that VP neurons exhibit a lower AP threshold and greater AP amplitude than OT neurons, and may serve to differently tune the firing properties and responses to neuromodulators of the respective neuronal types.

sodium channels; vasopressin; oxytocin; supraoptic; paraventricular

oxYTOCIN (OT) and vasopressin (VP) are neurohypophysial hormones involved in critical functions ranging from lactation and labor (OT) to fluid and blood pressure homeostasis (VP). The release of these hormones from neurohypophysial axon terminals is a function of the rate and pattern of action potential activity in the parent hypothalamic neurons (Poulain and Wakerley 1982), located in the supraoptic (SON), paraventricular (PVN), and various accessory nuclei (see Armstrong 1995, 2004 for reviews). This activity is shaped by synaptic inputs and several intrinsic ionic currents, and both OT and VP are preferentially released by bursting action potential activity, albeit with different forms in the two cell types. Whereas much is known about many currents underlying firing in these neurons, such as the depolarizing afterpotential prominent in VP neurons and potassium currents that give rise to spike afterhyperpolarizations in both cell types, less is known about the sodium currents underlying their action potentials. In addition to determining spike threshold, sodium currents can shape the width and height of spikes and thereby influence the amount

Address for reprint requests and other correspondence: R. Scroggs, Dept. of Anatomy and Neurobiology, Univ. of Tennessee Health Science Center, 855 Monroe Ave., Memphis, TN 38163 (e-mail: rscroggs@uthsc.edu). and time course of voltage-gated calcium influx as well as activate the potassium currents that repolarize the neuron. Tanaka et al. (1999) determined that most OT and VP SON neurons contained mRNA for $\mathrm{Na}_{\mathrm{V}} 1.2$ and $\mathrm{Na}_{\mathrm{V}} 1.6$ channels as well as $\beta_{1}$ and $\beta_{2}$ auxiliary subunits, and they additionally found that prolonged activation of (unidentified) SON neurons with salt loading ( $2 \% \mathrm{NaCl}$ in drinking water for 7 days) altered the size and properties of both fast and persistent sodium currents.

A previous current-clamp study using sharp electrodes revealed that the action potential properties of VP and OT neurons differed. In particular, spike height was lower, and threshold elevated, in OT neurons examined from slices of female rats (Stern and Armstrong 1996). These differences could relate to potassium and/or sodium current differences. In the present study we isolated fast sodium currents in dissociated OT and VP neurons from adult rats using whole cell recordings to determine which properties might underlie these differences in action potentials. We further reexamined some single-spike properties of identified OT and VP neurons using whole cell current-clamp recordings from hypothalamic slices from a recent study (Teruyama et al. 2008).

\section{METHODS}

All animal procedures were carried out according to an animal protocol reviewed and approved by the University of Tennessee Health Science Center Institutional Animal Care And Use Committee.

\section{Voltage-Clamp Experiments:}

Dissection. SON neurons were isolated either from coronal slices $(250 \mu \mathrm{M})$ of hypothalamus (see Wang and Armstrong 2012 for more details) or from a ventral thick slice hand cut with iris scissors (see Foehring and Armstrong 1996 for details). In either case, subjects were random cycling, virgin female adult rats (150-250 g, SpragueDawley; Harlan Laboratories, Indianapolis, IN). Data were acquired from 26 rats. Rats were perfused transcardially under deep anesthesia (pentobarbital sodium, $50 \mathrm{mg} / \mathrm{kg}$ ip) with a low- $\mathrm{Na}^{+}$artificial cerebrospinal fluid (ACSF), where $\mathrm{NaCl}$ was replaced by an equiosmolar amount of sucrose. ACSF was oxygenated with $95 \% \mathrm{O}_{2}$ and $5 \% \mathrm{CO}_{2}$. The SON was cut out under a stereomicroscope, and the pieces were incubated at $36^{\circ} \mathrm{C}$ for $0.5 \mathrm{~h}$ in ACSF containing (in $\mathrm{mM}$ ) $124 \mathrm{NaCl}$, $3 \mathrm{KCl}, 1.24 \mathrm{KH}_{2} \mathrm{PO}_{4}, 26 \mathrm{NaHCO}_{3}, 1.3 \mathrm{MgCl}_{2}, 2.4 \mathrm{CaCl}_{2}, 10$ glucose, and $2 \mathrm{mg} / \mathrm{ml}$ protease (type 2; Sigma-Aldrich) and continuously bubbled with $5 \% \mathrm{CO}_{2}-95 \% \mathrm{O}_{2}$. Pieces were washed in Tyrode's solution. Individual neurons were isolated by trituration, immediately transferred to a plastic $35-\mathrm{mm}$ petri dish where many adhered to the bottom, and superfused with Tyrode's solution (composition below).

Whole cell patch recordings. Patch electrodes were fabricated from soda lime capillary glass (B4416-1; Scientific Products) with the use 
of a Narishige two-stage vertical puller, coated with Sylgard (Dow Corning) to about $200 \mu \mathrm{m}$ from the tip, and fire-polished to a final resistance of $0.8-2.0 \mathrm{M} \Omega$ with a Narishige microforge. The patch electrodes were filled with a solution containing (in mM) $140 \mathrm{CsF}$, $1 \mathrm{MgCl}_{2}, 10 \mathrm{NaCl}, 11$ EGTA, and $10 \mathrm{HEPES}$, adjusted to $\mathrm{pH} 7.2$ with $\mathrm{CsOH}$. Giga-ohm seals were obtained in Tyrode's solution containing (in $\mathrm{mM}$ ) $140 \mathrm{NaCl}, 4 \mathrm{KCl}, 2 \mathrm{MgCl}_{2}, 2 \mathrm{CaCl}_{2}, 10$ glucose, and 10 HEPES, adjusted to $\mathrm{pH} 7.4$ with $\mathrm{NaOH}$. $\mathrm{Na}^{+}$currents were isolated by switching the solution around the patched neuron to solution containing (in $\mathrm{mM}$ ) $50 \mathrm{NaCl}, 112.5$ tetraethylammonium chloride (TEA), $2 \mathrm{CaCl}_{2}, 0.5 \mathrm{CdCl}_{2}$, and $10 \mathrm{HEPES}$, adjusted to $\mathrm{pH} 7.4$ with TEA-OH.

Data acquisition. Data acquisition was carried out using Clampex 8.2 (Axon Instruments) commanding an Axopatch 2A or 2B interfaced to the computer with a $1322 \mathrm{~A}$ series Digidata (Axon Instruments). The amplifier was tuned to null whole cell capacitance and optimize clamp speed and series resistance $\left(R_{\mathrm{s}}\right)$ compensation. Prediction and $R_{\mathrm{s}}$ compensation were set to $80-85 \%$. Data were filtered at $5 \mathrm{kHz}$, and all $\mathrm{Na}^{+}$currents were leak subtracted using the P/4 method.

Voltage dependency of activation. Data on the voltage dependency of activation were acquired from OT and VP neurons soon after establishment of whole cell patch configuration, recording of a whole cell capacity transient, and subsequent tuning of the amplifier. Neurons were held at $-90 \mathrm{mV}$ and given 10-ms-long test potentials (TPs) to -70 through $+50 \mathrm{mV}$ in $5-\mathrm{mV}$ increments at a frequency of 0.2 Hz. Current amplitude vs. voltage $(I-V)$ curves were converted to conductance according to the formula $g=I /\left(V_{\mathrm{t}}-V_{\mathrm{r}}\right)$, where $V_{\mathrm{t}}$ is the $\mathrm{TP}$ and $V_{\mathrm{r}}$ is the reversal potential. $V_{\mathrm{r}}$ was determined by extrapolation of a line fitted by eye to the last 3 or 4 data points that were negative to $0 \mathrm{pA}$. To estimate the voltage at which half the current was activated $\left(V_{\mathrm{a}}\right)$, the conductance vs. voltage $(g-V)$ curves were fitted with the Boltzmann equation: $1 /\left\{1+\exp \left[\left(V_{\mathrm{a}}-V_{\mathrm{t}}\right) / k\right]\right\}$, where $k$ is the slope factor. Before fitting, the values of $V_{\mathrm{t}}$ originally set in the Clampex protocol were adjusted for the voltage error $\left(V_{\text {err }}\right)$ resulting from $R_{\mathrm{s}}$ remaining after compensation. $R_{\mathrm{s}}$ was estimated (in most cases) from capacity transients recorded before nulling of whole cell compensation and $R_{\mathrm{s}}$ compensation, using the formula $R_{\mathrm{s}}=$ (whole cell capacitance/tau) $\times$ fraction of $R_{\mathrm{s}}$ compensation (usually 0.8 ). $V_{\text {err }}$ at each TP was calculated using the formula $V_{\mathrm{err}}=R_{\mathrm{s}} I$ and was subtracted from the corresponding original values of $V_{\mathrm{t}}$ set in Clampex. The $I-V$ curves were graphed and fitted with the above Boltzmann function using corrected values for $V_{\mathrm{t}}$.

Voltage dependence of steady-state inactivation. Neurons were given 500-ms conditioning potentials $(\mathrm{CP})$ to voltages ranging from -100 to $-30 \mathrm{mV}$ from a holding potential (HP) of $-90 \mathrm{mV}$, followed by TPs to $-5 \mathrm{mV}$ to assess the degree of inactivation incurred. The neurons were held at $-90 \mathrm{mV}$ for $5 \mathrm{~s}$ in between cycles of CP and TP. Normalized current amplitude was fitted with a Boltzmann function: $1 /\left\{1+\exp \left[\left(V_{\mathrm{m}}-V_{\mathrm{h}}\right) / k\right]\right\}$, where $V_{\mathrm{m}}$ is the CP voltage, $V_{\mathrm{h}}$ is the voltage at which half the current was inactivated, and $k$ is the slope factor.

Time course of recovery from inactivation. Neurons were given $10-\mathrm{ms}$ CPs to $-5 \mathrm{mV}$ from an $\mathrm{HP}$ of $-90 \mathrm{mV}$ to induce inactivation, followed by a recovery period at $-90 \mathrm{mV}$ ranging from 1 to $5,000 \mathrm{~ms}$. Each recovery period was immediately followed by a $10-\mathrm{ms}$ TP to -5 $\mathrm{mV}$ to assess the fraction of current available for activation. In between each TP and the subsequent $\mathrm{CP}$, neurons were held at -90 $\mathrm{mV}$ for $5 \mathrm{~s}$. Normalized current amplitude vs. recovery period was fitted with a double-exponential function: $f_{1} \times\left[1-\exp \left(-t / \tau_{1}\right)\right]+$ $\left(1-f_{1}\right) \times\left[1-\exp \left(-t / \tau_{2}\right)\right]$, where $f_{1}$ and $\left(1-f_{1}\right)$ are fitting parameters, $t$ is time, and $\tau_{1}$ and $\tau_{2}$ are time constants.

Action potential analysis. Single spikes were analyzed from whole cell current-clamp recordings in the SON, previously collected in the course of previous experiments using hypothalamic slices (e.g., Teruyama and Armstrong 2007; Teruyama et al. 2008). Animals (adult virgin female rats) and slices were prepared as described above. The
ACSF consisted of (in mM) $124 \mathrm{NaCl}, 3 \mathrm{KCl}, 2 \mathrm{CaCl}_{2}, 1.3 \mathrm{MgSO}_{4}$, $1.24 \mathrm{NaH}_{2} \mathrm{PO}_{4}, 25 \mathrm{NaHCO}_{3}, 0.2$ ascorbic acid, and 10 D-glucose $(\mathrm{pH}=7.4$; $\sim 290 \mathrm{mosmol} / \mathrm{kgH}_{2} \mathrm{O}$ ). The membrane potential was adjusted to just below spike threshold with DC current (range, -54 to $-68 \mathrm{mV}$ ), and a single spike was evoked with a 5-ms current pulse. Three to five spikes evoked from a given neuron at a similar membrane potential $( \pm 1 \mathrm{mV})$ were averaged. Spike threshold was determined from Axograph as the point where spike rise time exceeded $50 \mathrm{mV} / \mathrm{ms}$. Maximum slope of the spike upstroke was calculated from the peak of the derivative.

\section{Immunohistochemistry}

After recordings were completed, the pipette tip was lowered gently through the recorded neuron until it touched the bottom of the dish and the tip was gently broken off. In the majority of cases, a small glass shard remained, impaling the neuron to the petri dish. A box surrounding the neuron and number beside the box were then scratched into the petri dish for later identification. After one or two neurons in a dish had been recorded, the ACSF was removed and replaced with fixative (4\% $p$-formaldehyde- $0.2 \%$ picric acid) in phosphate-buffered saline (PBS: $0.01 \mathrm{M}$ Na-phosphate buffer, $0.15 \mathrm{M}$ $\mathrm{NaCl} ; \mathrm{pH} 7.4)$. Neurons were fixed for $1-3$ days at $4^{\circ} \mathrm{C}$, and the fixative was then gently washed with three changes of PBS and the neurons were incubated in a cocktail of antibodies for VP- and OT-neurophysins. VP neurons were identified by a polyclonal antibody (VP-NP; provided by Alan Robinson) raised in rabbit against VP-neurophysin and used at a 1:20,000 dilution. OT neurons were identified by a monoclonal antibody (PS 36 or PS 38; provided by Harold Gainer, NIH) raised in mouse against OT-neurophysin and used at a 1:5,000 dilution. The primary antibodies were dissolved in PBS containing $0.5 \%$ Triton-X (PBS-TX) and $0.04 \%$ sodium azide. After incubation in primary antibodies overnight at $4{ }^{\circ} \mathrm{C}$, the neurons were rinsed in three changes of PBS-TX and then incubated in a cocktail of two secondary antibodies: Alexa Fluor488-conjugated goat anti-rabbit IgG and Alexa Fluor594-conjugated goat anti-mouse IgG (Invitrogen, Eugene, OR). Photographs were captured using a digital camera (Sensyscam; Photometrics) with IPLabs software (Scanalytics, Fairfax, VA). Neurons were considered as either OT or VP types only if positive staining of one antibody was accompanied by a negative reaction with the other. A small minority of neurons were labeled with both antibodies and were not used for analysis in the present study. An example of an identified neuron is shown in Fig. 1.

\section{RESULTS}

\section{Current Density and Voltage Dependency of Activation}

Previous studies have shown that inward $\mathrm{Na}^{+}$currents in rat OT and VP neurons are completely blocked by tetrodotoxin (TTX) (Shevchenko et al. 2004; Teruyama and Armstrong 2005). Experiments on current density and voltage dependency of activation were carried out in 20 VP neurons and 13 OT neurons identified immunochemically (Fig. 1). Noticeable $\mathrm{Na}^{+}$ current was typically first observed at TPs around $-45 \mathrm{mV}$, and peak $\mathrm{Na}^{+}$current was typically evoked by TPs near -5 to $0 \mathrm{mV}$ (Fig. 2B). No significant difference between OT and VP neurons was detected in this regard. However, peak $\mathrm{Na}^{+}$ currents in VP neurons averaged 9,045 $\pm 939 \mathrm{pA}$, which was significantly greater than the average of $3,735 \pm 575 \mathrm{pA}$ observed for peak current in the OT neurons (Fig. 2, $A$ and B; $P<0.05$, Student's $t$-test). The difference in average peak current between OT and VP neurons was not due to a difference in the size of the respective neuronal somata. When normalized according to whole cell capacitance $(12.2 \pm 0.8 \mathrm{pF}$ 

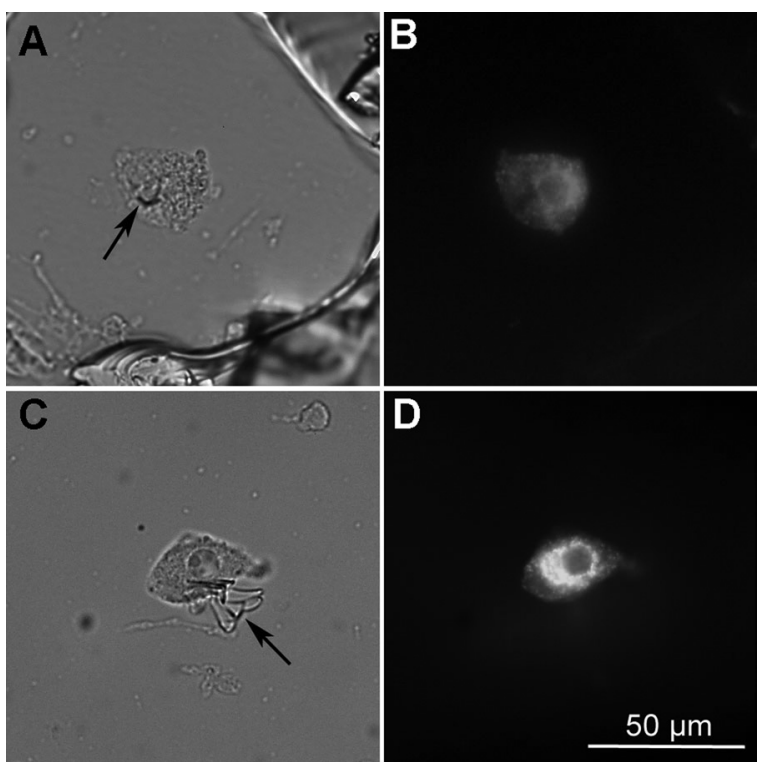

Fig. 1. Immunochemical identification of dissociated oxytocin (OT) and vasopressin (VP) neurons. A: brightfield image of an OT neuron. A small shard of pipette glass is visible (arrow). B: immunofluorescence for OT-neurophysin (NP) using Alexa Fluor 594-labeled secondary antibody. $C$ : brightfield image of a VP neuron. A large shard of pipette glass is visible (arrow). $D$ : immunofluorescence for VP-NP using Alexa Fluor-488 labeled secondary antibody.

for OT and $13.4 \pm 0.7 \mathrm{pF}$ for VP, not significantly different), $\mathrm{Na}^{+}$current density was significantly greater for VP neurons compared with OT neurons (Fig. $2 C ; P<0.05$, Student's $t$-test). Peak conductance normalized according to whole cell capacitance was also significantly greater for VP neurons compared with OT neurons (Fig. 2, $D$ and $E ; P<0.05$, Student's $t$-test). On the other hand, the voltage at which half the current was activated $\left(V_{\mathrm{a}}\right)$ was nearly identical for OT and VP neurons $(-13.4 \pm 1.1$ and $-13.3 \pm 1.4 \mathrm{mV}$, respectively; Fig. $2 D)$. The slope of the conductance vs. voltage curves $(k)$ was also for the same for OT and VP neurons, averaging $8.3 \pm$ 3 and $8.3 \pm 0.2$, respectively.

\section{Macroscopic Inactivation}

The macroscopic inactivation of the $\mathrm{Na}^{+}$currents was estimated in the same OT and VP neurons as described above over a range of TPs from around -10 to $+15 \mathrm{mV}$. For both types of neurons, the macroscopic inactivation rate was best fitted with a double-exponential function at all TPs, with the faster tau ranging from $\sim 0.7$ to $0.3 \mathrm{~ms}$ and a slower tau averaging around $2 \mathrm{~ms}$ (Fig. 3). A fast and slow tau accounted for $\sim 70 \%$ and $30 \%$, respectively, of the overall fit. There did not appear to be a significant difference between OT and VP neurons regarding macroscopic inactivation. However, a statistical analysis was not performed because the differences in current amplitude between OT and VP neurons caused differences in the TPs delivered to the respective neuronal types after adjustment for the effects of series resistance (Fig. 3).

\section{Steady-State Inactivation and Recovery from Inactivation}

No significant difference was detected between OT and VP neurons regarding the voltage dependence of steady-state inactivation or the time course of recovery from inactivation. The voltage at which half of $\mathrm{Na}^{+}$current was inactivated over 500-ms CPs $\left(V_{\mathrm{h}}\right)$ averaged $-64.0 \pm 1.5(k=5.4 \pm 0.2, n=$ $12)$ and $-62.6 \pm 1.4 \mathrm{mV}(k=5.7 \pm 0.1, n=22)$ for OT and VP neurons, respectively (Fig. 4A). Recovery from inactivation occurred at two distinct rates, with corresponding values of $\tau$ averaging $6.6 \pm 0.8$ and $396 \pm 60 \mathrm{~ms}$ for OT neurons $(n=15)$ and $8.2 \pm 0.8$ and $310 \pm 33 \mathrm{~ms}$ for VP neurons $(n=24$; Fig. $4 B$ ). The fitting parameters, indicating how much of the overall fit is attributed to the faster vs. slower time constant, also did not vary significantly between OT and VP neurons. The fitting parameter associated with the faster time constant $\left(f_{1}\right)$ averaged $0.847 \pm 0.019$ and $0.802 \pm 0.020$, respectively, for OT and VP neurons. In each case the fitting parameter associated with the slower time constant was equal to $1-f_{1}$ with the same standard error: $0.153 \pm 0.019$ for OT neurons and $0.198 \pm$ 0.020 for VP neurons.

\section{Action Potential Properties}

The data from the analysis of single action potentials from 28 OT and 19 VP neurons are shown in Table 1. We analyzed properties that might be most strongly related to underlying sodium currents, including spike height, threshold, and maximum slope (Fig. 5, Table 1). VP neurons had significantly larger spikes from rest and a faster upstroke than OT neurons.
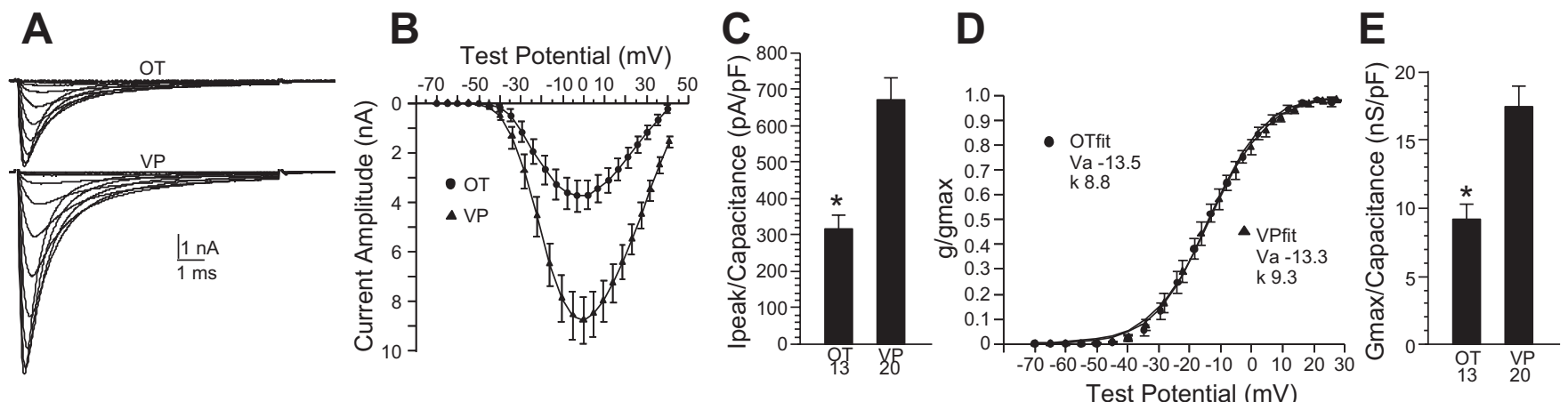

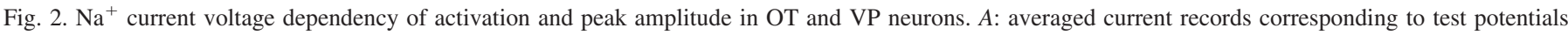

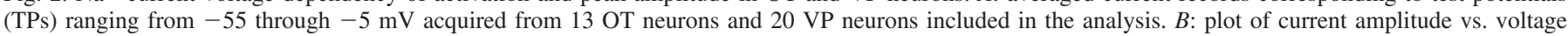

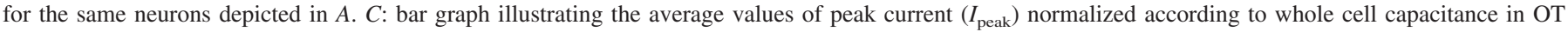

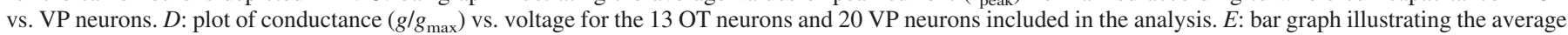

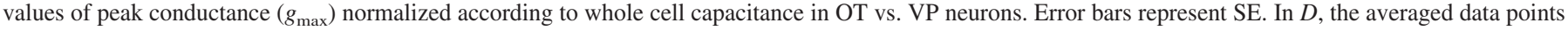

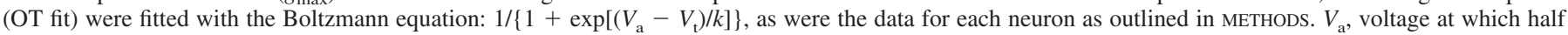
the current was activated; $V_{\mathrm{t}}$, test potential; $k$, slope factor. 

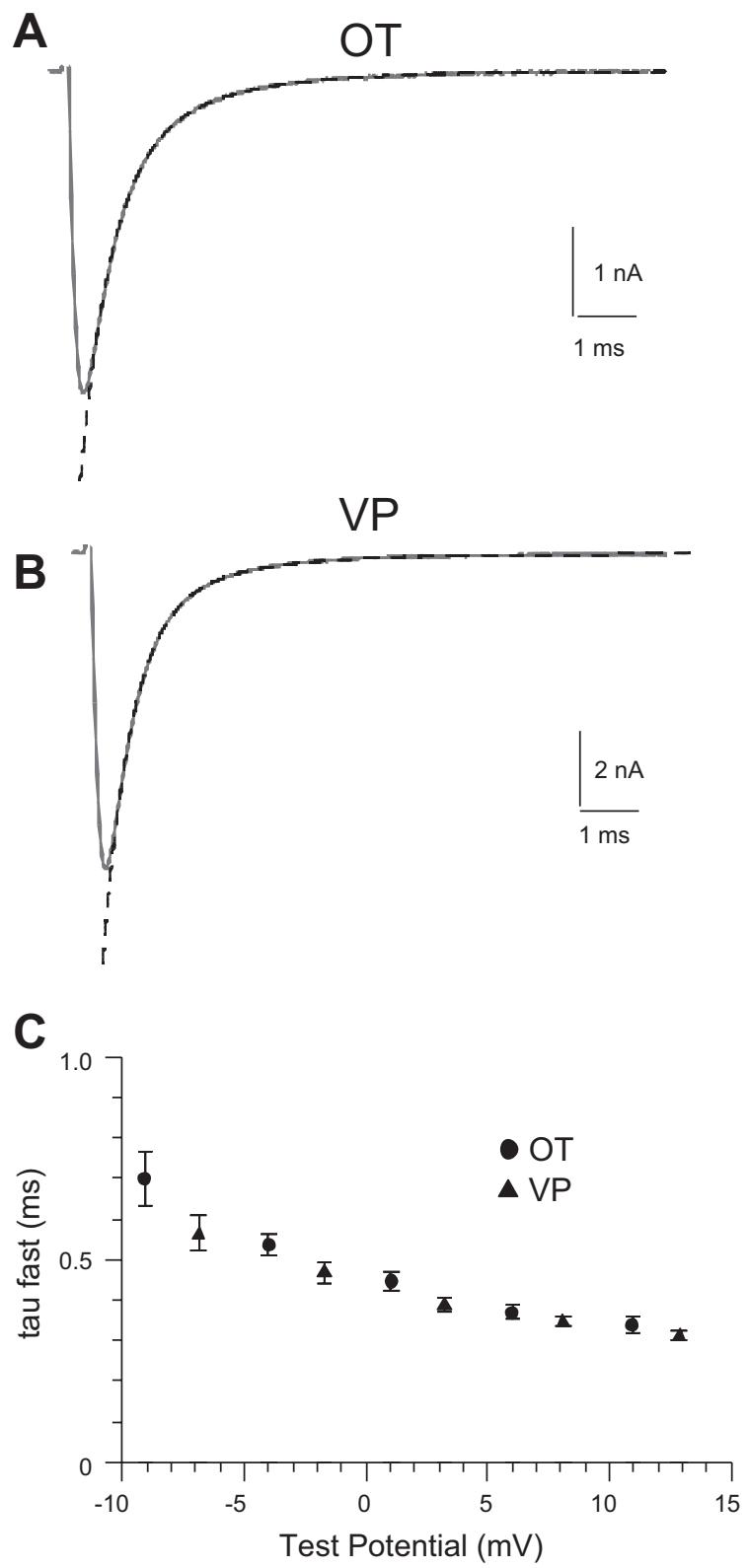

D

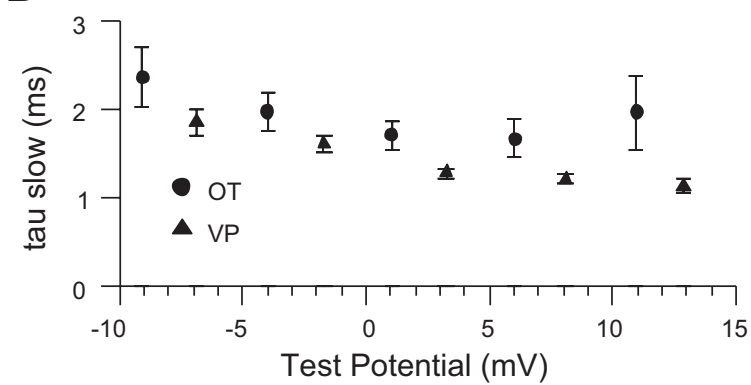

Fig. 3. Macroscopic inactivation rates for OT and VP neurons. $A$ and $B$ : demonstration of the fit of a double exponential to the macroscopic inactivation of $\mathrm{Na}^{+}$currents recorded from OT $(A)$ and VP neurons $(B)$. The currents shown are the averages of the same 13 OT neurons and 20 VP neurons included in Fig 2, evoked with voltage commands to $-5 \mathrm{mV}$. $C$ and $D$ : plot of fast $(C)$ and slow macroscopic inactivation rate $(D)$ for OT (circles) and VP neurons (triangles) given voltage commands to -10 through $+15 \mathrm{mV}$. The actual test potentials have been adjusted for the effects of series resistance (see METHODS).
A

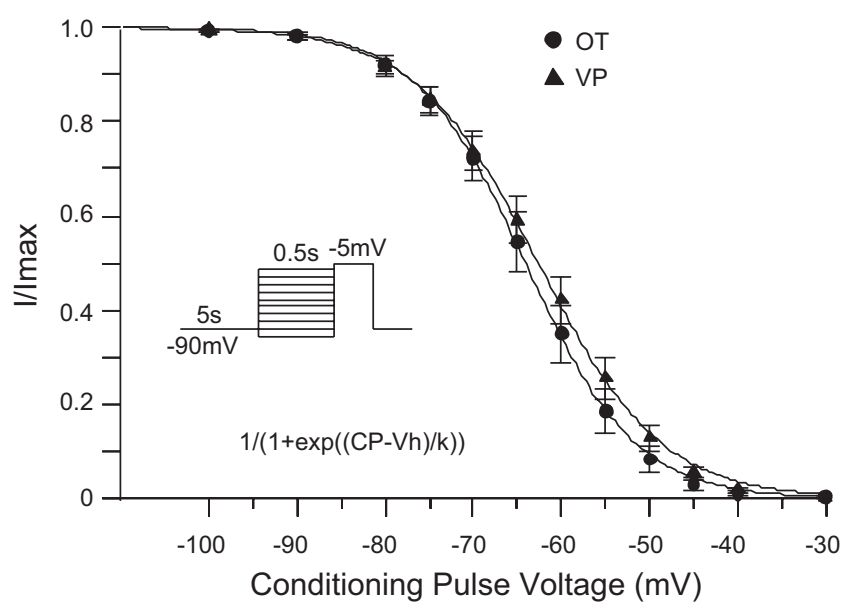

B

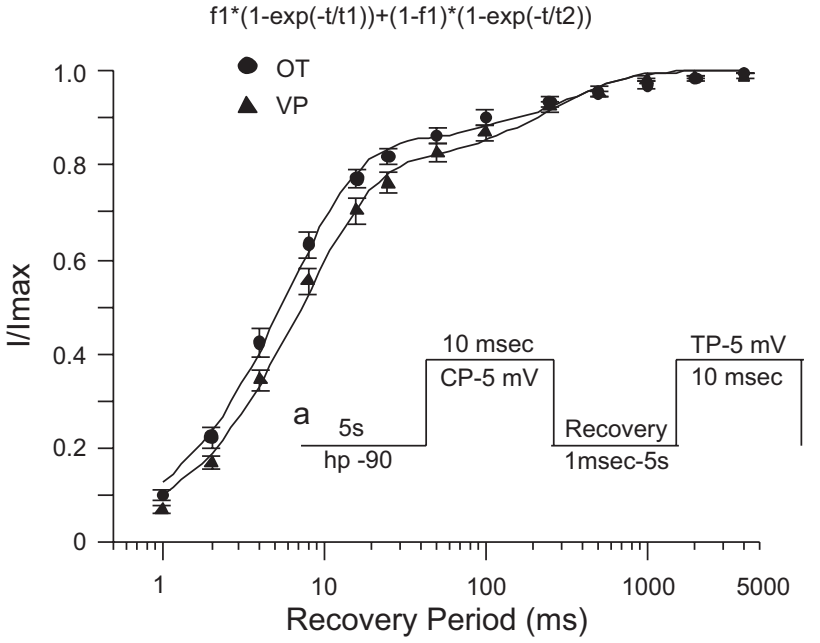

Fig. 4. Comparison of steady-state inactivation and recovery from inactivation between OT and VP neurons. A: voltage dependence of steady-state inactivation for OT (circles) vs. VP neurons (triangles). The averaged data points were fitted with the Boltzmann function: $1 /\left\{1+\exp \left[\left(V_{\mathrm{m}}-V_{\mathrm{h}}\right) / k\right]\right\}$, where $V_{\mathrm{m}}$ is the conditioning potential voltage, $V_{\mathrm{h}}$ is the voltage at which half the current is inactivated, and $k$ is the slope factor. $B$ : time course of recovery from inactivation for OT (circles) vs. VP neurons (triangles). The averaged data points were fitted with the double-exponential function: $f_{1} \times\left[1-\exp \left(-t / \tau_{1}\right)\right]+(1-$ $\left.f_{1}\right) \times\left[1-\exp \left(-t / \tau_{2}\right)\right]$.

No statistical difference was found in threshold or in the membrane potential just before the test spike was evoked. Since spikes were evoked over a range of membrane potentials $(\sim 10 \mathrm{mV})$ that could influence threshold via partial steadystate $\mathrm{Na}^{+}$channel inactivation, the correlations of baseline $V_{\mathrm{m}}$ with threshold and rise time were examined. Threshold in OT neurons was correlated with $V_{\mathrm{m}}\left(r=0.63, r^{2}=0.39, P \leq\right.$ $0.0004)$, whereas in VP neurons it was not $\left(r=0.27, r^{2}=\right.$ $0.07, P>0.27$; Fig. 6). $V_{\mathrm{m}}$ weakly influenced spike height in OT neurons $\left(r=0.43, r^{2}=0.19, P \leq 0.02\right)$ but was not significantly correlated with spike height in VP neurons $(r=$ $0.40, r^{2}=0.16, P>0.09$ ). These data suggest that $\sim 40 \%$ of the variance in threshold in OT neurons was accounted for by the $V_{\mathrm{m}}$ from which the spike was evoked. In contrast, the maximum slope of the upstroke was not significantly correlated with $V_{\mathrm{m}}$ in either cell type. 
Table 1. Properties of action potentials in OT and VP neurons

\begin{tabular}{lccccc}
\hline \hline & $n$ & Holding $V_{\mathrm{m}}, \mathrm{mV}$ & Threshold, $\mathrm{mV}$ & Height, $\mathrm{mV}$ & Maximum Slope, $\mathrm{mV} / \mathrm{ms}$ \\
\hline OT neurons & 28 & $-61.8 \pm 0.7$ & $-39.0 \pm 0.8$ & $89.3 \pm 1.3$ & $216.1+13.5$ \\
VP neurons & 19 & $-63.9 \pm 0.9$ & $-40.1 \pm 1.0$ & $93.8 \pm 1.6$ & $<0.03 \pm 16.3$ \\
$P$ value & & $>0.07$ & $>0.37$ & $<0.03$ & $<0.03$ \\
\hline
\end{tabular}

Values are means \pm SE for oxytocin (OT) and vasopressin (VP) neurons. $V_{\mathrm{m}}$, membrane potential; $n=$ no. of cells.

We also examined the decrease in spike amplitude and maximum slope that occurred for both OT and VP neurons during trains of action potentials. Separate groups of neurons were depolarized for $1 \mathrm{~s}(0.2-0.35 \mathrm{nA})$ to evoke firing at $\sim 60$ $\mathrm{Hz}(\mathrm{OT}: 60.2 \pm 2.21 \mathrm{~Hz}, n=14$; VP: $61.2 \pm 2.21 \mathrm{~Hz}, n=$ $14)$, a rate previously shown sufficient to evoke retrograde peptide release (Wang and Armstrong 2012) (Fig. 7A). To compare the time course of spike changes through the train for both cell types, spike amplitude and maximum slope were plotted for the first 40 spikes for all neurons, since all neurons fired at least 40 spikes. The change in the maximum slope of the spike upstrokes was well fit with a double exponential. Whereas maximum slope was greater for VP neurons during the first part of the train, as expected from the study of single spikes described above, the curves converged after about 150 ms, or $\sim 10$ spikes (Fig. $7 B$ ), due to the slower second component of decay in VP neurons compared with the second component in OT neurons. In contrast, spike amplitude was higher for VP than OT neurons throughout the train (Fig. 7C). This curve was complex due to the relatively large difference

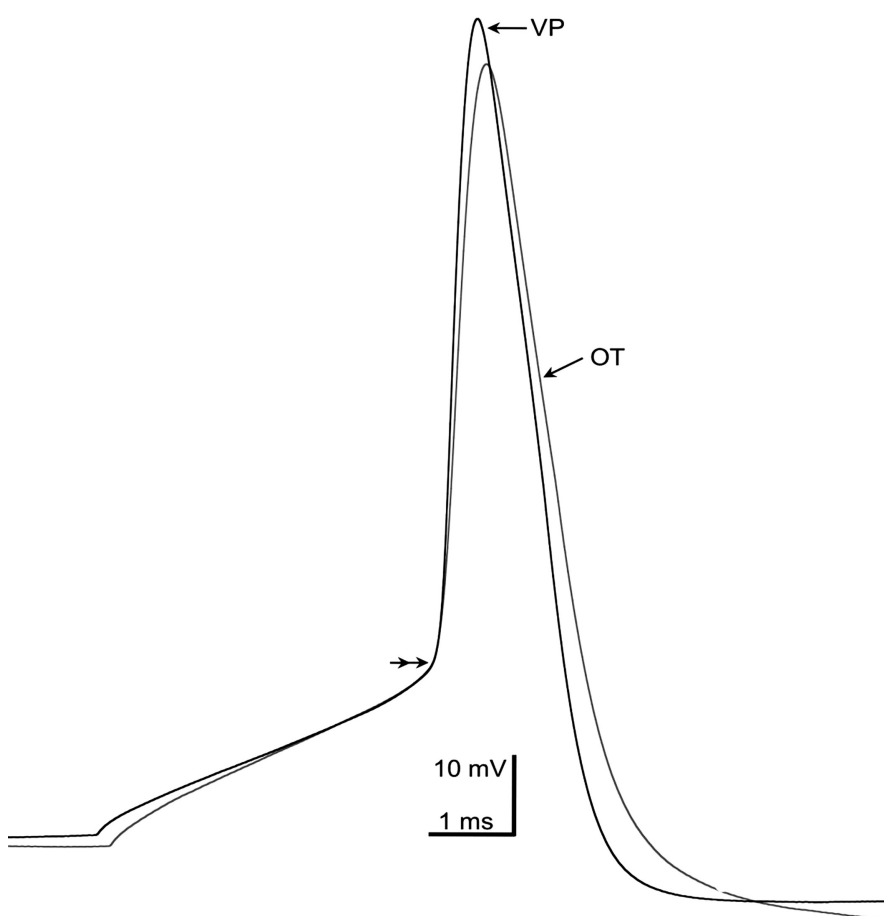

Fig. 5. Representative action potentials from OT (gray trace) and VP (black trace) neurons. Action potentials were generated from 5-ms depolarizing current injections. The 2 action potentials were aligned at threshold (double arrowhead). Threshold values were $-39.5 \mathrm{mV}$ for the OT neuron and -42.8 $\mathrm{mV}$ for the VP neuron. Note the slower rise time of the OT neuron (166.7 $\mathrm{mV} / \mathrm{ms}$ ) compared with the VP neuron $(236.4 \mathrm{mV} / \mathrm{ms})$ and the greater amplitude of the VP neuron $(+29.8 \mathrm{mV}$ peak; $93.9 \mathrm{mV}$ from baseline of -64.2 $\mathrm{mV}$ ) compared with the OT neuron $(+26.7$ peak; $88.4 \mathrm{mV}$ from baseline of $-61.8 \mathrm{mV})$. between the first and second spikes in both neuron types (Fig. $7, A$ and $C$ ) and also due to a very slow change after $\sim 250 \mathrm{~ms}$. After the first spike, the change was well fit with a single exponential to $\sim 250 \mathrm{~ms}$. Thereafter, the small, slow changes in amplitude were approximately linear in both cell types.

\section{DISCUSSION}

The only significant difference observed between the two neuronal types regarding whole cell $\mathrm{Na}^{+}$currents in this study was the larger density of $\mathrm{Na}^{+}$current in VP neurons compared with OT neurons. It is possible that the difference in current density observed between OT and VP neurons could be due to a difference in single-channel conductance, rather than the
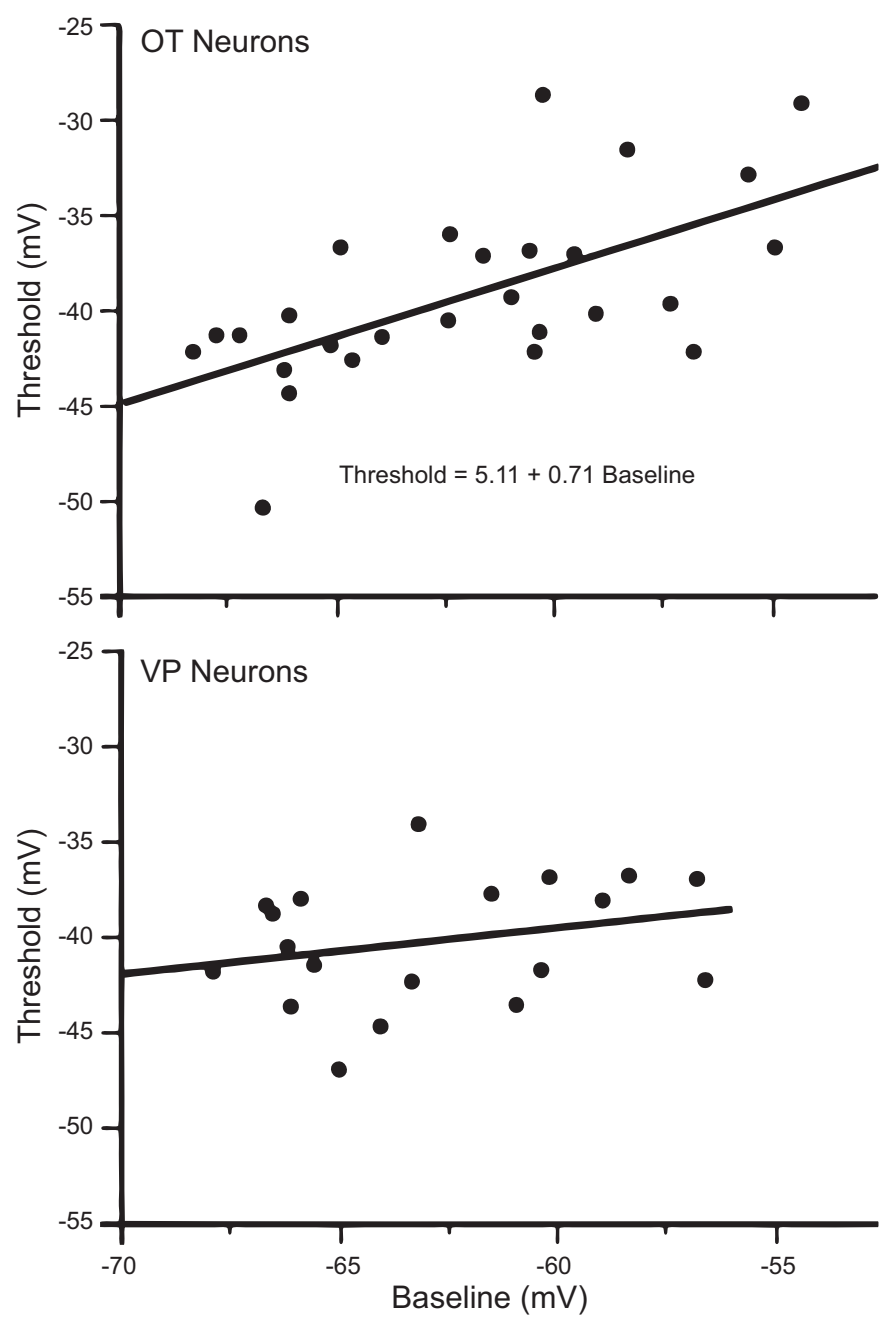

Fig. 6. Spike threshold plotted against baseline membrane potential $\left(V_{\mathrm{m}}\right)$ in OT and VP neurons. Top: in OT neurons, spike threshold was positively correlated with $V_{\mathrm{m}}$. Bottom: in VP neurons, no significant correlation was observed. See text for details. 

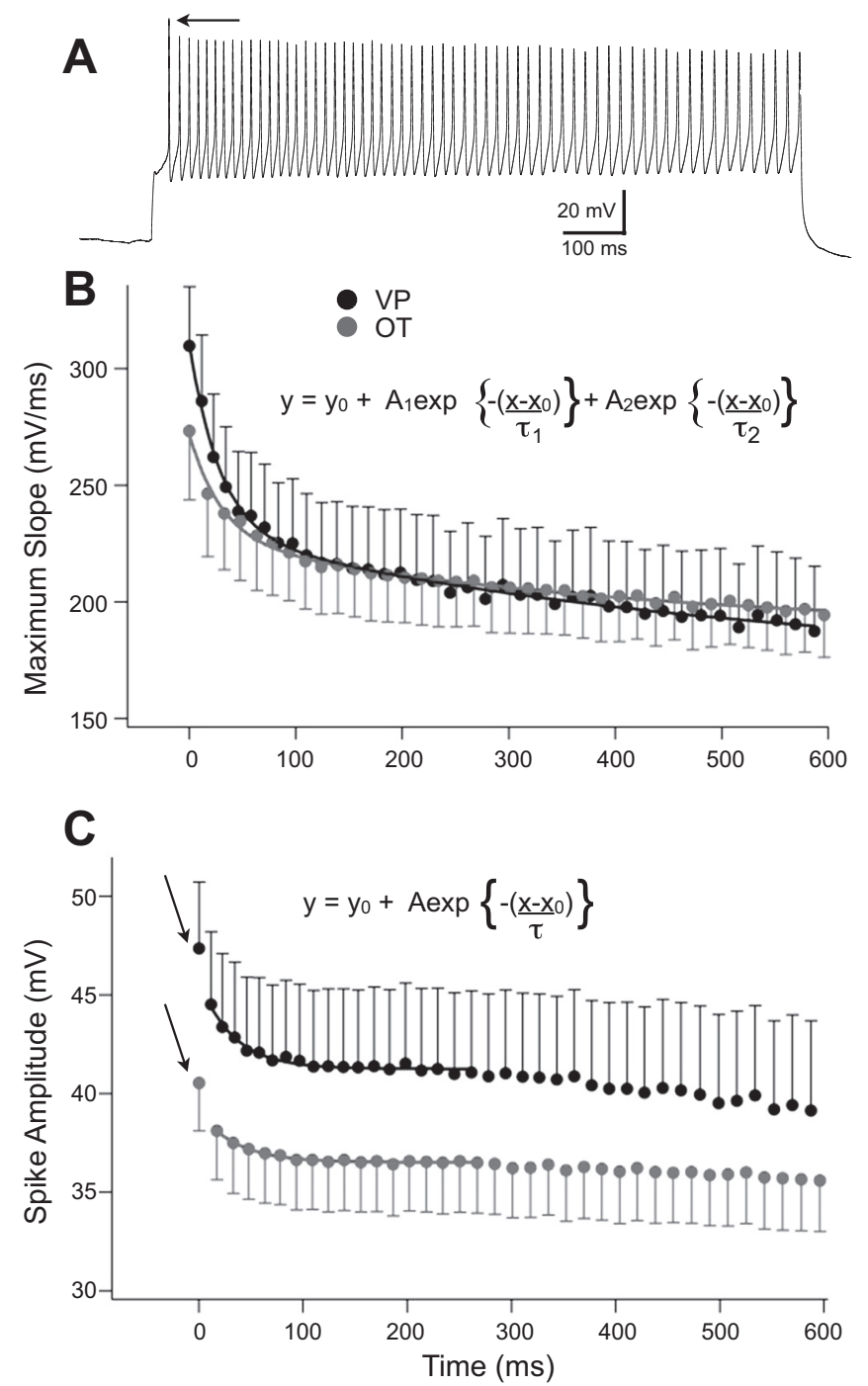

Fig. 7. Plots of spike maximum slope and spike absolute amplitude during trains of $\sim 60 \mathrm{~Hz}$ (see text). A: example of spike train from a VP neuron evoked with depolarizing current. Note the large change in spike amplitude from the first (arrow) to second spike, characteristic of most neurons of both types. $B$ : a reduction in the maximum slope over time was well fit with 2 exponentials in both cell types (VP: $\tau_{1}=28.6 \pm 2.2 \mathrm{~ms}, \tau_{2}=492.9 \pm 171 \mathrm{~ms}$; OT: $\tau_{1}=$ $30.1 \pm 3.4 \mathrm{~ms}, \tau_{2}=403.7 \pm 124 \mathrm{~ms}$ ). The faster components decayed with a similar time constant in the 2 cell types, whereas the curves converged around $150 \mathrm{~ms}$ due to differences in the slower component. $C$ : spike amplitude showed approximately a $5 \%$ reduction between the first (arrows) and second spikes in both cell types and thereafter decayed with a single exponential to $\sim 250 \mathrm{~ms}$, after which amplitude continued to slightly decrease with a very slow time course that was near linear in both cell types. Inclusion of the first spike also prevented reasonable fits, so this point was excluded. In contrast to the maximum slope, the amplitude difference between OT and VP neurons was maintained throughout the train.

number of channels expressed. However, we are not aware of any studies showing marked differences in single-channel conductance for TTX-sensitive $\mathrm{Na}^{+}$channels in different neuronal types.

The fast and slow macroscopic inactivation rates for both neuronal types appeared to be similar. Also, the voltage dependencies of activation and inactivation were essentially overlapping for the two cell types, and both were well fitted with similar Boltzmann functions. Our value for $V_{\mathrm{a}}$ (approximately $-13 \mathrm{mV}$ ) was more depolarized than that of Tanaka et al.
(1999) and had a shallower slope. This difference may reflect our adjustment of test potentials for uncompensated series resistance $(\sim 20 \%)$. Both studies used nearly identical internal and external solutions, with the exception that in the Tanaka et al. (1999) study the external solution had $1 \mathrm{mM} \mathrm{CaCl}_{2}$ whereas the present study used $2 \mathrm{mM} \mathrm{CaCl}{ }_{2}$. In both studies, the voltage dependence and slope of inactivation curves were quite similar ( $V_{\mathrm{h}}$ of approximately $-63 \mathrm{mV}, k=5-6 \mathrm{mV}$ in both studies). For both neuronal types in the present study, recovery from inactivation exhibited a fast time constant averaging around $8 \mathrm{~ms}$, which is similar to that reported for $\mathrm{Na}_{\mathrm{V}} 1.2$ and $\mathrm{Na}_{\mathrm{V}} 1.6$ channels (Herzog et al. 2003; Rush et al. 2005). We have not been able to find a previous report of a slower time constant of around $300-400 \mathrm{~ms}$ for $\mathrm{Na}_{\mathrm{V}} 1.2$ or $\mathrm{Na}_{\mathrm{V}} 1.6$ channels, which we observed for both OT and VP neurons. This may be because in many studies on TTXsensitive $\mathrm{Na}^{+}$channels, recovery is monitored over relatively short times, and the data are fitted with a single exponential (for example, see Herzog et al. 2003 and Rush et al. 2005). In this study, we monitored the time course of recovery out to 5 $s$ and fitted the data with a double-exponential function. In any case, our data regarding two rates of recovery from inactivation are consistent with our observation that macroscopic inactivation proceeds at two distinct rates, which also suggests the presence of multiple inactivation states.

The difference between OT and VP neurons regarding $\mathrm{Na}^{+}$ channel density seems consistent with observed differences in the two types regarding action potential height, maximum slope, and threshold. The higher $\mathrm{Na}^{+}$channel density in VP vs. OT neurons could underlie the higher action potential heights and faster rate of rise observed for VP neurons. In addition, the voltage recordings suggest that action potential threshold is more sensitive to membrane potential in OT neurons vs. VP neurons. This also might be explained by the lower $\mathrm{Na}^{+}$ channel density observed for OT neurons vs. VP neurons. Possibly, steady-state inactivation of $\mathrm{Na}^{+}$channels, at membrane potentials over which action potential firing was observed, would have a greater impact on action potential threshold in OT neurons because OT neurons start out with a smaller pool of available $\mathrm{Na}^{+}$channels. Although threshold was not statistically different between the two cell types in this study using whole cell recordings, in a previous examination of OT and VP neurons with sharp electrodes we did find a significantly elevated spike threshold in OT neurons as well as a significantly lower action potential height here (Stern and Armstrong 1996). Overall, the data regarding action potential threshold for OT and VP neurons compared with their respective $\mathrm{Na}^{+}$channel densities are consistent with findings of a previous study, which suggested there is a strong inverse correlation between action potential threshold and whole cell $\mathrm{Na}^{+}$channel conductance (Matzner and Devor 1992). The differences in action potential threshold (and current density) observed for OT neurons vs. VP neurons could depend on whether the axon originates from the axon hillock, near the cell body, or from a proximal dendrite. However, this seems unlikely. Although both cases have been documented for both OT and VP neurons, the proportion of cases where axons arose from the axon hillock vs. a proximal dendrite did not differ significantly between OT vs. VP neurons (Stern and Armstrong 1998). 
On the other hand, there was a rather remarkable similarity between OT and VP neurons regarding several measures of $\mathrm{Na}^{+}$channel function, including fast and slow macroscopic inactivation rates, voltage dependency of activation and steady-state inactivation, and fast and slow time constants of recovery from inactivation. These similarities between OT and VP neurons could be explained by the observation of Tanaka et al. (1999) that both OT and VP neurons express predominately $\mathrm{Na}_{\mathrm{V}} 1.2$ and $\mathrm{Na}_{\mathrm{V}} 1.6 \mathrm{Na}^{+}$channels. In particular, the rates of recovery from inactivation observed in this study could explain aspects of firing behavior shared by both OT and VP neurons. The fast time constant for recovery from inactivation $(\sim 8 \mathrm{~ms})$ could be an average of the behavior of the mixture of $\mathrm{Na}_{\mathrm{V}} 1.2$ and $\mathrm{Na}_{\mathrm{V}} 1.6 \mathrm{Na}^{+}$channels and could serve to limit the maximal firing frequency observed for both neurons $(\sim 70 \mathrm{~Hz}$ in whole cell patch recordings). The slow time constant for recovery from inactivation could be involved in the decrease in action potential height observed following the onset of rapid firing in both OT and VP neurons. A significant fraction of $\mathrm{Na}^{+}$channels $(\sim 20 \%)$ could be expected to fail to recover from inactivation following the initial spike at fast firing rates. However, this effect would be gradually offset as the pool of slow inactivated channels increases in size over the course of subsequent action potentials.

The lower $\mathrm{Na}^{+}$channel density of OT neurons could make OT neuronal firing particularly vulnerable to neuromodulation. The simplest case imagined might be any neurotransmitter action that alters membrane potential for a time sufficient to engage the voltage dependence of spike threshold we demonstrated. In addition, in many neurons, $\mathrm{Na}^{+}$channel availability can be modulated by transmitters operating through $\mathrm{G}$ proteincoupled receptor activation (see Catterall 2002, 2010 for reviews). For example, phosphorylation of $\mathrm{Na}^{+}$channels has been shown to enhance slow inactivation, thereby inhibiting firing when neurons remain depolarized (Maurice et al. 2004). It follows that neurons with a lower channel density would be more sensitive to such a modulation.

Despite a rich and long history of neuromodulation in SON neurons (see Armstrong, 1995; Chakfe and Bourque 2001; Renaud and Bourque 1991; Shibuya et al. 2000 for reviews), there has been no reported demonstration that $\mathrm{Na}^{+}$currents are specifically targeted by neurotransmitters in either VP or OT neurons. Beyond action potential generation, the suggested importance of $\mathrm{Na}^{+}$channels in firing patterns in the SON (Boehmer et al. 2000; Inenaga et al. 1993; Li and Hatton 1996), and their upregulation during states such as dehydration (Tanaka et al. 1999) and diabetes (Klein et al. 2002), indicates the investigation of transmitter modulation of these channels is strongly warranted.

\section{ACKNOWLEDGMENTS}

We thank Dr. Robert Foehring for reviewing an earlier version of the manuscript.

\section{GRANTS}

This work was supported by National Institute of Neurological Disorders and Stroke Grants NS23941-19 and R56 NS23941-20A (to W. E. Armstrong).

\section{DISCLOSURES}

No conflicts of interest, financial or otherwise, are declared by the authors.

\section{AUTHOR CONTRIBUTIONS}

R.S., L.W., R.T., and W.E.A., conception and design of research; R.S., L.W., R.T., and W.E.A., performed experiments; R.S., L.W., R.T., and W.E.A., analyzed data; R.S., L.W., R.T., and W.E.A., interpreted results of experiments; R.S., L.W., R.T., and W.E.A., prepared figures; R.S., L.W., R.T., and W.E.A., R.S., L.W., R.T., and W.E.A., drafted manuscript; R.S., L.W., R.T., and W.E.A., edited and revised manuscript; R.S., L.W., R.T., and W.E.A., approved final version of manuscript.

\section{REFERENCES}

Armstrong WE. Morphological and electrophysiological classification of hypothalamic supraoptic neurons. Prog Neurobiol 47: 291-339, 1995.

Armstrong WE. Hypothalamic supraoptic and paraventricular nuclei. In: The Rat Nervous System (3rd ed.), edited by Paxinos G. Sydney: Elsevier, 2004, p. 369-388.

Boehmer G, Greffrath W, Martin E, Hermann S. Subthreshold oscillation of the membrane potential in magnocellular neurones of the rat supraoptic nucleus. J Physiol 526: 115-128, 2000.

Catterall WA. Molecular mechanisms of gating and drug block of sodium channels. Novartis Found Symp 241: 206-218, 2002.

Catterall WA. Signaling complexes of voltage-gated sodium and calcium channels. Neurosci Lett 486: 107-116, 2010.

Chakfe Y, Bourque CW. Peptidergic excitation of supraoptic nucleus neurons: involvement of stretch-inactivated cation channels. Exp Neurol 171: 210-218, 2001.

Foehring RC, Armstrong WE. Pharmacological dissection of high-voltageactivated $\mathrm{Ca}^{2+}$ current types in acutely dissociated rat supraoptic magnocellular neurons. J Neurophysiol 76: 977-983, 1996.

Herzog RI, Cummins TR, Ghassemi F, Dib-Hajj SD, Waxman SG. Distinct repriming and closed-state inactivation kinetics of $\mathrm{Na}_{\mathrm{v}} 1.6$ and $\mathrm{Na}_{\mathrm{V}} 1.7$ sodium channels in mouse spinal sensory neurons. $J$ Physiol 551: 741-750, 2003.

Inenaga K, Nagatomo T, Kannan H, Yamashita H. Inward sodium current involvement in regenerative bursting activity of rat magnocellular supraoptic neurones in vitro. $J$ Physiol 465: 289-301, 1993.

Klein JP, Craner MJ, Cummins TR, Black JA, Waxman SG. Sodium channel expression in hypothalamic osmosensitive neurons in experimental diabetes. Neuroreport 13: 1481-1484, 2002.

Li Z, Hatton GI. Oscillatory bursting of phasically firing rat supraoptic neurones in low- $\mathrm{Ca}^{2+}$ medium: $\mathrm{Na}^{+}$influx, cytosolic $\mathrm{Ca}^{2+}$, and gap junctions. J Physiol 496: 379-394, 1996.

Maurice N, Mercer J, Chan CS, Hernandez-Lopez S, Held J, Tkatch T, Surmeier DJ. D2 dopamine receptor-mediated modulation of voltagedependent $\mathrm{Na}^{+}$channels reduces autonomous activity in striatal cholinergic interneurons. J Neurosci 24: 10289-10301, 2004.

Matzner O, Devor M. $\mathrm{Na}^{+}$conductance and the threshold for repetitive neuronal firing. Brain Res 597: 92-98, 1992.

Poulain DA, Wakerley JB. Electrophysiology of hypothalamic magnocellular neurones secreting oxytocin and vasopressin. Neuroscience 7: 773-808, 1982.

Renaud LP, Bourque CW. Neurophysiology and neuropharmacology of hypothalamic magnocellular neurons secreting vasopressin and oxytocin. Prog Neurobiol 36: 131-169, 1991.

Rush AM, Dib-Hajj SD, Waxman SG. Electrophysiological properties of two axonal sodium channels, $\mathrm{Na}_{\mathrm{V}} 1.2$ and $\mathrm{Na}_{\mathrm{V}} 1.6$, expressed in mouse spinal sensory neurons. J Physiol 564.3: 803-815, 2005.

Shevchenko T, Teruyama R, Armstrong WE. High-threshold, Kv3-like potassium currents in magnocellular neurosecretory neurons and their role in spike repolarization. J Neurophysiol 92: 3043-3055, 2004.

Shibuya I, Kabashima N, Ibrahim N, Setiadji SV, Ueta Y, Yamashita H. Pre- and postsynaptic modulation of the electrical activity of rat supraoptic neurones. Exp Physiol 85: 145S-151S, 2000.

Stern JE, Armstrong WE. Changes in the electrical properties of supraoptic nucleus oxytocin and vasopressin neurons during lactation. J Neurosci 16: 4861-4871, 1996.

Stern JE, Armstrong WE. Reorganization of the dendritic trees of oxytocin and vasopressin neurons of the rat supraoptic nucleus during lactation. $J$ Neurosci 18: 841-853, 1998.

Tanaka M, Cummins TR, Ishikawa K, Black JA, Ibata Y, Waxman SG. Molecular and functional remodeling of electrogenic membrane of hypothalamic neurons in response to changes in their input. Proc Natl Acad Sci USA 96: 1088-1093, 1999. 
Teruyama R, Armstrong WE. Calcium-dependent fast depolarizing afterpotentials in vasopressin neurons in the rat supraoptic nucleus. J Neurophysiol 98: 2612-2621, 2007.

Teruyama R, Armstrong WE. Enhancement of calcium-dependent afterpotentials in oxytocin neurons of the rat supraoptic nucleus during lactation. $J$ Physiol 566: 505-518, 2005.
Teruyama R, Lipschitz DL, Wang L, Ramoz GR, Crowley WR, Bealer SL, Armstrong WE. Central blockade of oxytocin receptors during mid-late gestation reduces amplitude of slow afterhyperpolarization in supraoptic oxytocin neurons. Am J Physiol Endocrinol Metab 295: E1167-E1171, 2008.

Wang L, Armstrong WE. Tonic regulation of GABAergic synaptic activity on vasopressin neurones by cannabinoids. J Neuroendocrinol 24: 664-673, 2012.

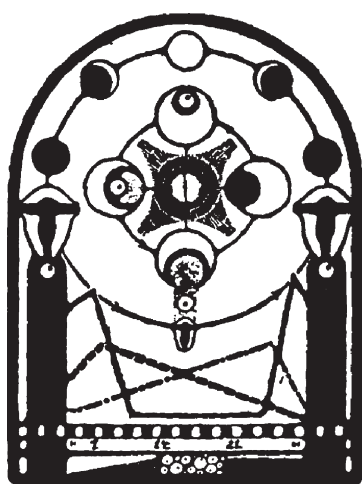

